\title{
Quantitative and qualitative measures of open-field social behavior in the rat*
}

\author{
ALEX POPLAWSKY, DAVID A. JOHNSON, and DEBORAH POPLAWSKY \\ Ohio University, Athens, Onio 45701
}

\begin{abstract}
Rat pairs were observed in two experiments in an open-field testing situation for a period of 10 consecutive days. Measures of contact time, aggressive, submissive, and other social behaviors were recorded during 5-, or 5- and 15-min periods. As in previous studies, contact time increased over days throughout the 10-day period. Aggressive, submissive, and other social behaviors observed in the open field were fairly consistent over days, but large qualitative differences were sometimes found between individual pairs of rats. There was a high correlation between 5- and 15-min observation periods for all variables measured.
\end{abstract}

A variety of experiments (Eckman, Meltzer, \& Latané, 1969; Latané, Joy, Meltzer, Lubell, \& Cappell, 1972; Latané, Nesbitt, Eckman, \& Rodin, 1972; Poplawsky \& Johnson, 1973) are currently using open-field contact time as a dependent variable. Most of these studies use a 5 -min observation period. It is possible that this limited time period is an insufficient sample of open-field behaviors. Other experiments (Grant, 1963; Grant \& Mackintosh, 1963) have analyzed qualitative aspects of social behavior in the open field. While it is clear that the contact time increases regularly over successive days of observation, the consistency or predictability of day-to-day changes in qualitative aspects of open-field behavior have not been systematically investigated. The purposes of this study were: (1) to evaluate the use of 5vs 15 -min observation periods for both qualitative and quantative observations, and (2) to determine the consistency of qualitative behaviors over days.

\section{EXPERIMENT I}

\section{Method}

Subjects. One hundred male hooded Long-Evans rats, 90-120 days old, from the Ohio University breeding colony were used in this study. Each rat was housed in a single cage under conditions of constant light, and maintained on an ad lib food-and-water schedule. Rats were assigned to pairs at random (one member's tail being marked for identification).

Apparatus. An open field similar to the one described by Latané (1969) was used as the setting for behavioral observations. The open field was $4 \mathrm{ft}$ in diam, surrounded by an 18 -in. wall. It was painted glossy white and all observations took place in a well-lit room. The E used clicks from a metronome to designa te 3 -sec time intervals, and used a stopwatch to measure contact time.

Procedure. The E placed each rat pair in the open field and allowed a 15-min habituation period for 3 days prior to behavioral observations. The rat pairs were observed for $5 \mathrm{~min}$ a day for a period of 10 days. Two Es were used throughout the experiment. Contact time and types of social behaviors were independently measured on alternate days by the two Es.

On each open-field test day, the rats were placed by pairs into

*This experiment was supported by Grant No. 0-2100-3660 from the Ohio University Research Foundation to David A. Johnson; Alex Poplawsky was supported by an NSF traineeship. the open field for a 5-min observation period. Time in direct physical contact was recorded on a stopwatch. Contact time was defined as any physical contact (bodily, hair, or vibrissae contact) except passive tail-to-tail contact. In addition, types of social behavior (aggressive, submissive, nonsocial, and social behaviors other than aggressive or submissive) were recorded at 3 -sec intervals in order of occurrence. The major behavioral patterns adopted from Grant and Mackintosh (1963) are categorized in Table 1 .

\section{Results}

Inter-O reliability coefficients were .97 (for contact time), and ranged between .84 and .92 for the different types of social behaviors over days. Analyses of variance revealed that contact time (Fig. 1a) significantly increased $(\mathrm{F}=21.66, \mathrm{df}=8,441, \mathrm{p}<.01)$ over days. Rat pairs spent an average of $131 \mathrm{sec}$ ( $44 \%$ of the available time) in direct physical contact.

Figure 2 represents the mean rate of social behaviors (aggressive, submissive, and other) per minute contact time over the 10 open-field observation days. Social

Table 1

\begin{tabular}{ll}
\hline \multicolumn{1}{c}{ Aggressive Behaviors } & Submissive Behaviors \\
\hline Threat & Freeze \\
Thrust & Crouch \\
Attack & Evade \\
Chase & Retreat \\
Bite & Flee \\
Biting groom & Passively receives bites \\
Olfactory genital contact (pushing) & Passively submits to \\
Attempted mount & sexual contacts laying \\
Crawl over & on back, feet extended \\
Crawl under pushing partner upward & \\
Full upright boxing posture & \\
\hline \multicolumn{1}{c}{ Other Social Behaviors } & Nonsocial Behaviors \\
\hline Attend & Explore \\
Approach & Self-groom \\
Investigate & No physical contact \\
Nose & \\
Side to side contact & \\
Lying on each other & \\
Brushing together while exploring & \\
Following behavior &
\end{tabular}



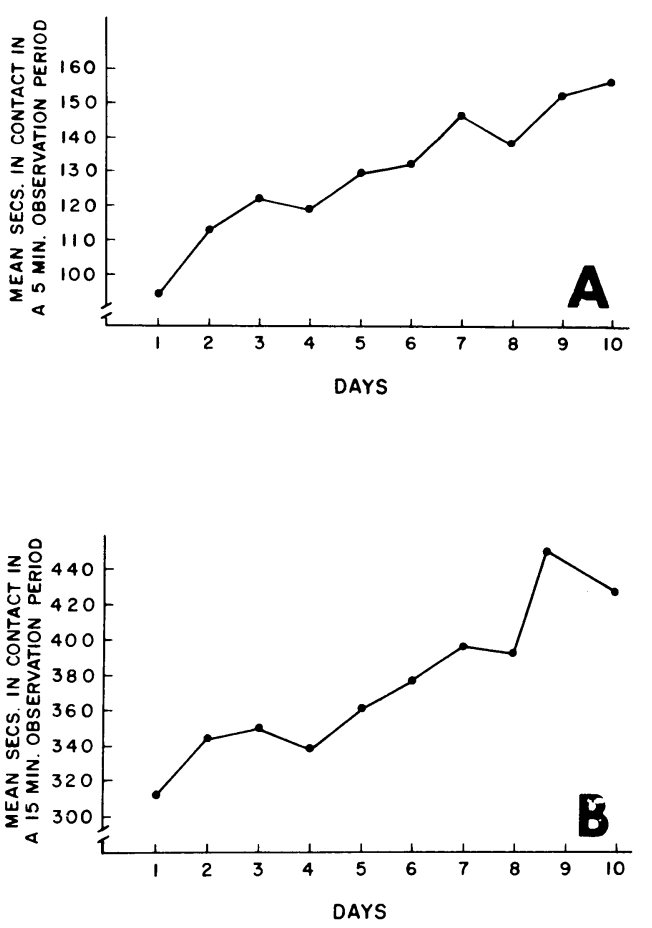

Fig. 1. (a) Mean seconds in direct physical contact in a 5-min observation period over a 10-day period (Experiment I). (b) Mean seconds in direct physical contact in a 15-min observation period over a 10-day period (Experiment II).
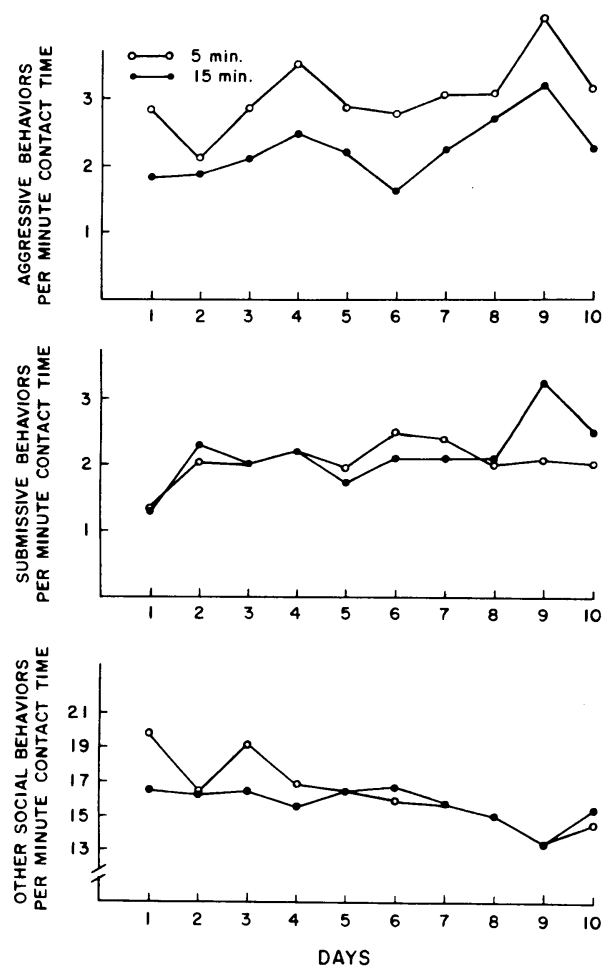

Fig. 2. Aggressive, submissive, and other social behaviors per minute contact time in 5 - and 15 -min observation periods over days. behaviors per minute contact time were computed in order to control the increase in contact time over days. Aggressive behaviors increased slightly over days $(\mathrm{F}=$ 2.10 , df $=9,44, \mathrm{p}<.05$ ), with considerable variability from day to day (due to large differences in individual aggressive behaviors). Submissive behaviors were very stable over days $(\mathrm{F}=0.96, \mathrm{df}=9,441, \mathrm{p}>.25)$, while other social behaviors decreased over days $(F=8.72, \mathrm{df}$ $=9,441, \mathrm{p}<.01)$.

\section{EXPERIMENT II}

Since most of the previous experiments using Latané's (1969) method of observation have utilized 5-min observation periods, this study was designed to compare a 5 -min observation period with a 15 -min observation period.

\section{Method}

Sixty male hooded Long-Evans rats, 90-120 days old, from the Ohio University breeding colony were used in this study. The apparatus and procedure were the same as the previous experiment except that the rat pairs were observed for a $15-\mathrm{min}$ period instead of a 5-min period. Behaviors were recorded after each of three successive 5-min intervals.

\section{Results}

Each rat pair spent an average of $375 \mathrm{sec}$, or $42 \%$ of the available time in direct physical contact. Contact time increased over days $(\mathrm{F}=6.0, \mathrm{df}=9 / 261, \mathrm{p}<.01)$ from $35 \%$ of the available time in contact on the 1 st day to $48 \%$ on the 10th day (Fig. 1b). Aggressive behaviors $(\mathrm{F}=2.42, \mathrm{df}=9 / 261, \mathrm{p}<.01)$ and submissive behaviors $(F=2.56$, df $=9 / 261, p<.01)$ per minute contact time slightly increased over days, while other social behaviors $(F=4.06, d f=9 / 261, p<.01)$ per minute contact time decreased over days (Fig. 2). Only a small percentage of the variance, however (aggressive, 2\%; submissive, 2\%; and other $6 \%$ ), in qualitative behaviors was accounted for by the days effect.

A comparison of social behaviors between each 5-and 15-min observation period is presented in Table 2 . Behaviors recorded each 5-min period are highly correlated with the social behaviors recorded at the end of a 15-min period for contact time, aggressive behavior, and submissive behavior.

Table 2

Correlations of Behaviors in Each 5-Min Time Interval With Total Social Behaviors in the 15-Min Observation Period for Contact Time, Aggressive, and Submissive Social Behaviors

\begin{tabular}{lccr}
\hline & $\begin{array}{c}\text { Contact } \\
\text { Time }\end{array}$ & Agg & Sub \\
\hline First 5-Min Period & .80 & .79 & .75 \\
Second 5-Min Period & .82 & .81 & .83 \\
Third 5-Min Period & .76 & .67 & .75 \\
\hline
\end{tabular}




\section{DISCUSSION}

The results of Experiments $I$ and II are consistent with previous investigations that reported an increase in gregariousness in rat pairs over days (Latané \& Glass, 1968; Latané, 1969). The rates of aggressive, submissive, and other social behaviors are fairly consistent over days. While the rates of aggressive or submissive behaviors were fairly consistent within pairs across days, there were large differences in the frequencies of these behaviors between pairs. Once a rat established dominance over his partner, their aggressive and submissive behaviors remained constant, although there were many differences between different rat pairs. Experiment II suggests that in the open-field-testing situation, 5- or 15-min observation periods produce comparable results for both quantitative and qualitative aspects of behavior.

\section{REFERENCES}

Eckman, J., Meltzer, J. D., \& Latané, B. Gregariousness in rats as a function of familiarity of environment. Journal of Personality \& Social Psychology, 1969, 11, 107-114.

Grant, E. C. An analy sis of the social behaviour of the male laboratory rat. Behaviour, 1963, 21, 246-259.

Grant, E. C. \& Mackintosh, J. H. A comparison of the social postures of some common laboratory rodents. Behaviour, 1963, 21, 246-259.

Latané, B. Gregariousness and fear in laboratory rats. Journal of Experimental Social Psychology, 1969, 5, 61-69.

Latané, B., \& Glass, D. C. Social and nonsocial attraction in rats. Journal of Personality \& Social Psychology, 1968, 9, 142-146.

Latané, B., Joy, V., Meltzer, J., Lubell, B., \& Cappell, H. Stimulus determinants of social attraction in rats. Journal of Comparative \& Physiological Psychology, 1972, 79, 13-21.

Latané, B., Nesbitt, P., Eckman, J., \& Rodin, J. Long- and short-term social deprivation and sociability in rats. Journal of Comparative \& Physiological Psychology, 197 2, 81, 69-75.

Poplawsky, A., \& Johnson, D. A. Open-field social behavior of rats following lateral or medial septal lesions. Physiology \& Behavior, 1973, 11, 845-854.

\title{
Isolation, serial position, and rehearsal in free recall*
}

\author{
FRANCIS S. BELLEZZA $\dagger$ and GREGORY P. HOFSTETTER $\dagger \dagger$ \\ Ohio University, Athens, Ohio 45701
}

\begin{abstract}
If the superior recall of isolated, high-priority items is the result of selective rehearsal, then recall of these items will depend on both serial position and retention interval in a single-trial free-recall task. Using presentation times of $2 \mathrm{sec}$ and $5 \mathrm{sec}$ per item, predictions made from the selective-rehearsal hypothesis were supported. With both presentation times, recall of words adjacent to the recalled isolated words was poorer than corresponding control words.
\end{abstract}

If one item in a list of items is made conspicuous with respect to the rest of the items, this item will be learned better. This is the von Restorff effect. Also, if Ss are instructed to especially remember particular items in a list, then these items will be better recalled. The term isolated in the present discussion is used to describe those items that are both made conspicuous and which the Ss are instructed to especially recall. One explanation for better recall under these conditions is that the Ss selectively rehearse the isolated items at the expense of the other items in the list (Jenkins \&

*This research was supported in part by Grant OURC 437 made to the first author by the Ohio University Research Committee. This paper is sponsored by D. A. Johnson, who takes full editorial responsibility for its contents.

tRequests for reprints should be sent to Francis S. Bellezza, Department of Psychology, Ohio University, Athens, Ohio 45701 .

+Now at Central Michigan University, Mount Pleasant, Michigan.
Postman, 1948; Waugh, 1969). The mechanism of rehearsal also plays an important role in the dual-storage models of Atkinson and Shiffrin (1968) and of Waugh and Norman (1965). The degree to which items have been rehearsed can explain the primacy effect in single-trial free-recall learning; and what items are being rehearsed at the time of recall can explain the recency effect (Rundus \& Atkinson, 1970; Glanzer, 1972). If the degree of selective rehearsal of an item is dependent both on its serial position and on its isolation, then the probability of recall of an item is also dependent on its serial position and isolation (Bellezza \& Cheney, 1973). More specifically: (a) Isolated items which appear at the beginning or middle of a list should be recalled with a higher probability than corresponding control items. This is because the greater rehearsal of these items will lead to a higher probability of their being coded into long-term store (LTS). (b) Isolated items appearing very late in the list will not reside in short-term store (STS) 